\title{
Regulation and the Risk of Inaction
}

\author{
Bryant Walker Smith
}

\section{Content}

27.1 Introduction . . . . . . . . . . . . . . . . . . . . . . . . . . . . . . . . 594

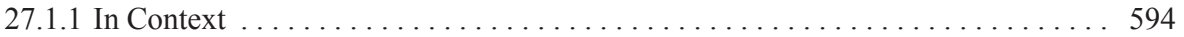

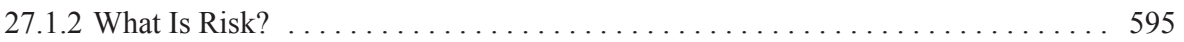

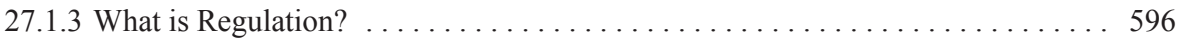

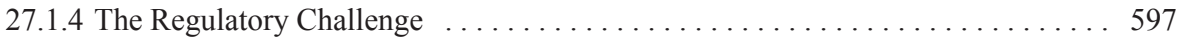

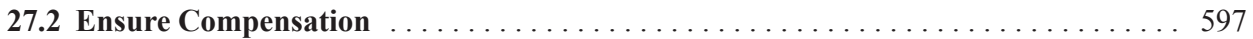

27.2.1 Expand Public Insurance . . . . . . . . . . . . . . . . . . . . . . . . . . . . . 597

27.2.2 Facilitate Private Insurance . . . . . . . . . . . . . . . . . . . . . . . 598

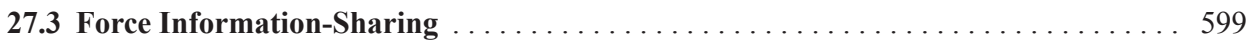

27.3.1 Privilege the Concrete . . . . . . . . . . . . . . . . . . . . . . . 599

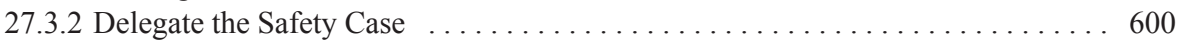

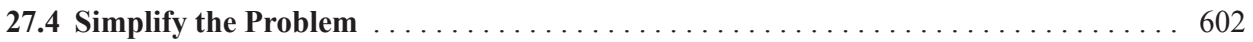

27.4.1 Limit the Duration of Risk . . . . . . . . . . . . . . . . . . . . . . . 602

27.4.2 Exclude the Extreme . . . . . . . . . . . . . . . . . . . . . . . . . 602

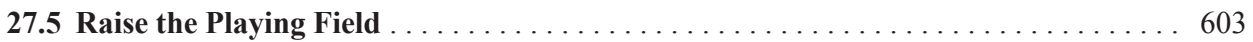

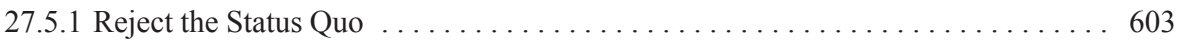

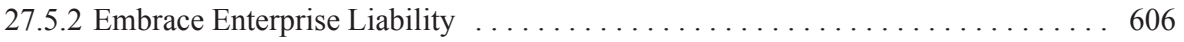

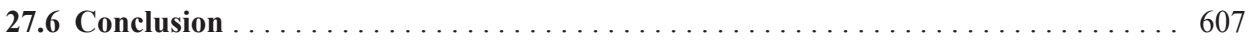

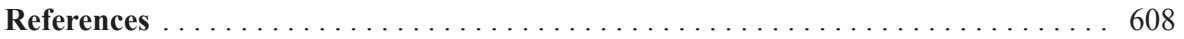

B. W. Smith $(\bowtie)$

University of South Carolina School of Law, USA

bryantws@civil.co.de 


\subsection{Introduction}

\subsubsection{In Context}

Two complex and conflicting objectives shape altruistic regulation of human activity: maximizing net social good and mitigating incidental individual loss. Eminent domain provides a superficially simple example: To build a road that benefits ten thousand people, a government evicts - and compensates - the ten people whose homes are in the way. But in many cases, individual loss is not fully compensable, most strikingly when that loss involves death: Whatever her actual detriment, a person who dies cannot be "made whole." And indeed, more than 30,000 people lose their lives on US roadways every year while more than 300 million obtain some direct or indirect benefit from motorized transport.

The promise that vehicle automation holds for highway safety raises difficult questions about regulation's social and individual objectives. Analyzing either objective requires topical and temporal definition of a manageable system in which costs and benefits can be identified, valued, and compared. With respect to net social good, what is the statistical value of a human life? Is a reduction in organ donations a "cost" of safer highways? Could aggressive deployment of particular technologies cause a backlash that ultimately undermines safety? Similarly, with respect to individual loss, how should injury or death be valued? Should culpability affect compensation? Who is entitled to it? The particular answers to these questions may depend on the domain - law, economics, ethics, the social sciences - from which they are drawn.

Vehicle automation exposes tension between the social and individual objectives. Externalities frequently accompany innovation: Inventors impose costs that they need not or cannot bear and create benefits that they cannot capture. Compensation of incidental injury may be one such cost, and socially desirable innovations like automation might be subsidized by shielding them from it. Calibrating net social good and individual loss can also create moral hazard: Safety might be discounted by innovators who are legally or effectively exempt from rules and immunized from lawsuits or by consumers who are assured of compensation for injury.

This tension exists against two related background conditions. The first is a preference for the status quo - a tendency that is reflected in administrative law, in tort law, and internationally in the precautionary principle. Many vehicle fatalities appear only in local obituaries, but a single automated vehicle fatality would end up on national front pages. The second is a failure by imperfectly probabilistic humans to accurately perceive risk. Drivers who speed around blind corners but fear traveling over bridges demonstrate this tendency to underestimate some risks and overestimate others.

This complex regulatory context leads to two fundamental questions: How should risk be allocated in the face of significant uncertainty - and who should decide? The range of actors includes the legislative, executive, and judicial branches of national and subnational governments, companies, standards organizations, consumers, and the public at large. Regulation can be prospective or retrospective, but it cannot be nonexistent: Administrative 
Table 27.1 Potential Regulatory Strategies

\section{Ensure sufficient compensation for those who are injured}

Expand public insurance

Force information-sharing by the private sector to enhance regulation

Privilege the concrete

Delegate the safety case

Simplify both the technical and the regulatory challenges in coordination

Limit the duration of risk

Exclude the extreme

Raise the playing field for conventional actors along with automated systems

Reject the status quo
Embrace enterprise liability

agencies that decline to establish safety requirements for automated vehicles merely leave this task to judges and juries after incidents have occurred.

The consequences of action or inaction are as stark as they are uncertain. Regulatory acts or omissions could cost lives in the near term by delaying or raising the price of automation technologies [28]. But they could also save lives in the longer term by protecting broad classes of innovation from the potential reputational damage that early tragedies or controversies could inflict. Charting the currents of abstract social gain and concrete human loss from vehicle automation requires appreciating the risks that regulation presents as well as those that it addresses.

This chapter first considers the nature of risk, the nature of regulation, and the challenge of regulating - in a broad sense - the increasing automation of motor vehicles. It then introduces four pairs of potential strategies to respond to this challenge, as summarized in Table 27.1 (above).

These strategies are not exhaustive. They may be unnecessary. And they may be insufficient. Some are obvious, some are unconventional, and some may well be both. Their purpose is to advance discussion of the proper role of the public sector-legislatures, administrative agencies, and courts - in addressing automation's challenges and opportunities.

\subsubsection{What Is Risk?}

Risk can mean so many things that, without context, it means not much at all. Broadly, "[t]he risk of a particular harm is the product of the probability of that harm and the severity of that harm; the risk of an act or omission is the sum of the risks of the particular associated harms" [20]. This actual risk, however, is merely theoretical: No actor can comprehensively inventory all associated harms or accurately determine their probabilities and magnitudes.

In practice, actual risk is therefore simplified into assessed and perceived risk. Assessed risk reflects a methodical attempt to objectively describe all significant harms within a defined system; this system might contemplate a broad range of harms, as in the case of an environmental impact statement, or a more narrow range, as in the case of a functional 
safety standard focused on physical injury to humans [20]. In contrast, perceived risk reflects an individual's subjective judgment about particular dangers; it may differ considerably from the assessed risk.

An internalized risk is one that is borne by the actor who creates it, regardless of whether that actor has correctly assessed or perceived that risk. Internalization is central to tort law's regulatory role: By forcing actors to bear more of the costs of their unreasonably dangerous behavior, tort law seeks to deter that behavior.

The financial risks imposed on these actors, however, are categorically different from the physical risks that these actors impose on others. In obligating these actors to pay damages to those they have injured, tort law also plays a compensatory role. Nonetheless, even if those who are injured succeed in recovering damages, they will still have been injured [20].

Accordingly, it is important to distinguish between reducing physical risk (a regulatory function) and shifting financial risk (a compensatory function). Some of the regulatory strategies introduced below may achieve one of these two objectives at the expense of the other.

\subsubsection{What is Regulation?}

Regulation checks and changes behavior. In its narrowest sense, the term refers only to rules enacted by an administrative agency. A more useful conception, however, encompasses a broad range of actions, including those illustrated in Figure 27.1 [24].

Regulation can be prospective (forward-looking) or retrospective (backward-looking). Prospective actions, shown on the left side, contemplate a generalized risk that has not manifested, as in the case of the federal performance requirements governing vehicle design. In

Figure 27.1 Quadrants of Regulation

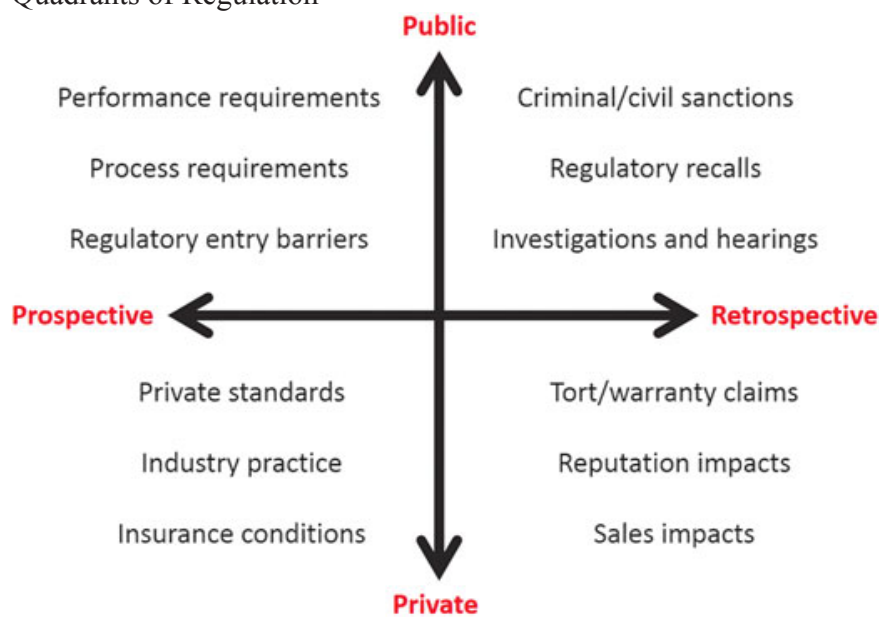


contrast, retrospective actions, shown on the right side, respond to the realization of a risk, as in the case of a tort claim by a person injured in a crash. The possibility of retrospective regulation, particularly if it is foreseeable, can affect behavior even if the risk is never realized.

Regulation can also be pursued by a public actor or by a private actor. Public actions, shown on the top, include typical functions of the state: setting requirements and conducting investigations. In contrast, private actions, shown on the bottom, generally involve relationships among private parties: a consensus among market participants, a contract between an insurer and its insured, or the tort duties of a manufacturer to those who are injured by its products.

Although this chapter focuses on public actors, these private relationships remain an important tool of public policy. A statutory requirement that drivers obtain sufficient insurance, for example, delegates some regulatory power to the private-sector insurance companies that then decide, subject to additional public regulation, how much any particular driver should be charged.

\subsubsection{The Regulatory Challenge}

For public regulators, the utilitarian challenge is to indirectly maximize net social good while indirectly mitigating incidental individual loss. With respect to vehicle automation, this means defining an appropriate system in which societal costs and benefits can be analyzed [20], checking that the incentives and disincentives for developers of automated systems are consistent with that system, reconciling these with the incentives and disincentives for other actors, and ensuring that those who are harmed have appropriate access to some means of compensation.

This chapter outlines four pairs of potential regulatory strategies that could advance these goals. Its focus on risk management by public actors complements earlier risk management proposals for private actors [21]. These strategies involve ensuring compensation by expanding public insurance and facilitating private insurance, forcing information-sharing by privileging the concrete and delegating the safety case, simplifying the problem by limiting the duration of risk and excluding the extreme, and raising the playing field by rejecting the status quo and embracing enterprise liability.

\subsection{Ensure Compensation}

\subsubsection{Expand Public Insurance}

Insurance can help reduce the financial burden placed on injured individuals and, potentially, the compensatory pressure placed on tort law. Ensuring that those who are physically injured by automated vehicles are able to recover for their injuries makes the occurrence of those injuries, at least from a public policy perspective, more justifiable. If the only 
avenue for that recovery, however, is litigation, product liability law may be forced to bend in ways that distort its regulatory function.

While an expansion of insurance has merit as a standalone initiative, it must be a condition of any reasonable proposal to subsidize vehicle automation by limiting tort remedies. Reducing a defendant's liability means reducing an injured individual's access to compensation. It also means depriving that individual of a sanctioned means of recourse: Suing a manufacturer, whatever its inefficiencies, is still preferable to sabotaging that company's products or undertaking other means of private retribution.

\subsubsection{Facilitate Private Insurance}

While private insurers can also provide compensation, their potential role as regulators is particularly promising. A well-functioning insurance market can generate useful data and desirable incentives. It can reduce uncertainty for those who might be plaintiffs as well as for those who are regularly defendants. Take two distinct examples: vehicle insurance and product liability insurance.

In the United States, most drivers and vehicle owners are required to carry insurance for harms inflicted with their vehicles. The required coverage varies by state and is generally far less than would be necessary to compensate for a serious injury or death; California, for example, requires only $\$ 15,000$ in coverage for injury or death to one person and $\$ 30,000$ in coverage for injury or death to more than one person [4]. The companies that offer this insurance tend to be subject to complex regulatory regimes that also vary by state; California even prescribes the primary factors to be used in pricing such insurance [5].

An alternative regime could respond much more flexibly to vehicle automation. Increasing and then enforcing insurance requirements could help internalize more crash costs, compensate injury more fully, shift some recovery from manufacturers toward negligent drivers, and enable consolidation of some product liability claims through subrogation. Reducing consumer-facing restrictions on insurers could free these companies to better tailor their products to reflect the actual risk posed by particular drivers in particular vehicles in particular conditions. This could in turn advantage those automated vehicles that actually represent a safety improvement.

In contrast to drivers, companies are generally not required by law to maintain product liability insurance. Indeed, one of the purposes of the corporate form is to protect shareholders from liability. Requiring such coverage, however, could provide a check on safety by engaging a third-party insurer in a regulatory role: In order to obtain affordable coverage - or coverage at all - a manufacturer would need to persuade the insurer that its products do not pose unreasonable risk. This would be another way to "delegate the safety case," to quote the section of the same name below.

The regimes created by Nevada and California to regulate automated vehicles already require companies seeking to test their systems on public roads to demonstrate financial capacity beyond typical state insurance requirements. California, for example, requires 
$\$ 5,000,000$ in the form of a certificate of insurance, a certificate of self-insurance, or a surety bond [3]. While this approach is promising, these heightened insurance requirements should apply to all vehicles rather than merely to automated vehicles undergoing testing. As the section of the same name argues below, such regulation should "raise the playing field" for conventional as well as automated vehicles.

\subsection{Force Information-Sharing}

\subsubsection{Privilege the Concrete}

Product development requires understanding, and as necessary shaping, external forces like law. If specific legal obligations, restrictions, or liabilities are impeding automated vehicle technologies, then would-be developers of those technologies should challenge those constraints. In short, they should identify the specific legal changes that they or their products require - and support these arguments with concrete data and careful analysis. If they do not, policymakers should ask why.

Although concerns have been raised for decades about the product liability implications of increasing vehicle automation [17], automakers tend to refer only broadly, if at all, to this potential challenge even as they announce plans to deploy increasingly advanced automation features. This apparent disconnect suggests either that the technologies themselves are not as imminent as popularly believed [22] or that the companies pursuing those technologies are not as concerned about general product liability as is commonly suggested.

In contrast, automakers have acted to address a more narrow liability question related to the installation or modification of automation systems. Several state legislatures have now clarified that, to quote Michigan law [12], manufacturers and subcomponent producers are "not liable and shall be dismissed from any action for alleged damages resulting from" such third-party installations or conversions "unless the defect from which the damages resulted was present" at the time of manufacture. This provision is largely a restatement of common law [22] and, like common law, does not unambiguously contemplate every potential modification claim. ${ }^{1}$

Notwithstanding this uncertainty, this experience demonstrates that established automakers can recognize potential legal issues, propose specific legislative remedies, and with the exception of California [34] - obtain their enactment. To the extent that automated vehicles depend on changes to vehicle codes [19], insurance requirements, or rules of liability, regulators should expect well-reasoned and well-supported arguments from their high-profile developers.

1 Consider two examples. In the first, the manufacturer fails to warn against a foreseeable modification of its vehicle; might that failure to warn constitute a "defect from which the damages resulted"? In the second, the subcomponent producer designs a sensor that is highly vulnerable to hacking; might that security vulnerability constitute a "defect from which the damages resulted"? 
Relying exclusively on companies to advance specific legal changes, however, can tend to preserve the status quo. Unlike conventional cars, low-speed shuttles and delivery robots generally have neither existing markets nor established companies to advocate for them. As a result, these applications of automation have been largely ignored in recent legislative and regulatory initiatives [22]. Accordingly, governments should also consider whether a dearth of specific proposals or concrete data can be explained by an inability rather than a disinclination to participate in the regulatory process.

In a sense, governments should approach policymaking with the same philosophy underlying public support of physical infrastructure and scientific research: Initiate what the private sector cannot or will not do. Broad mandates or basic conditions may be useful in driving or policing innovation, but attempts to closely tailor rules to products that do not yet exist could produce law that is premature and prejudicial.

\subsubsection{Delegate the Safety Case}

Vehicle automation is putting state regulators in a difficult position. Prominent examples come from Nevada and California, the two states whose departments of motor vehicles were directed to quickly enact regulations governing automated vehicles and automated driving. ${ }^{2}$ These regulations seek both to provide greater legal certainty to the developers of automated systems [16], [26], [31] and to restrict unreasonably dangerous products and practices [23].

Many states, however, already empower regulators to restrict the registration, modification, or operation of road vehicles on the basis of safety [19]. A New York statute, for example, permits the motor vehicle commissioner to "refuse to register any vehicle or class of vehicles for use on the public highways where he determines that the characteristics of such vehicle or class of vehicles make such vehicle or vehicles unsafe for highway operation" [14].

Alternative approaches to deploying automation systems, including pilot projects and aftermarket modifications, may implicate this authority more quickly than would traditional rollouts [22]. Long before the National Highway Traffic Safety Administration (NHTSA) promulgates rules for automated vehicles ${ }^{3}$ or even conducts investigations into incidents involving them, state regulators may be facing - or at least actively ignoring - the question of whether to revoke the registration of a vehicle retrofitted with a novel automation system.

Answering such a question will inevitably frustrate these regulators [31]. There is no consensus about how to define, or then how to demonstrate, the appropriate level of safety

2 Other states have enacted automated driving statutes without expressly requiring this rulemaking. 3 NHTSA has historically promulgated performance standards only for safety technologies that have already been widely deployed, although the eventual regulation of vehicle-to-vehicle (V2V) communications systems is likely to be an exception. 
for an automated vehicle or for the human-machine system to which it may belong [25] Moreover, the kind of regulation that is appropriate for an established automaker may differ considerably from the kind that is appropriate for a small startup or an individual tinkerer [22].

Although state vehicle agencies generally lack NHTSA's technical resources, they may have more regulatory flexibility. Federal motor vehicle safety standards (FMVSSs) are restricted to objective measures and to tests "capable of producing identical results when test conditions are exactly duplicated" [7], quoted in [35].

In contrast, state agencies may be bound by less demanding requirements of administrative process, which may afford them the discretion needed to gradually develop consistent practice. This flexibility could enable state regulators to address specific technologies without entrenching rules that are likely to become anachronistic and irreconcilable with those of other states.

To this end, "delegating the safety case" would mean requiring the developer of a vehicle automation system to publicly make and defend arguments about how well its system should perform and how well its system actually performs. In short:

1. A manufacturer documents its actual and planned product design, testing, and monitoring.

2. The manufacturer publicly presents this documentation in the form of a safety case.

3. The regulatory agency and interested parties comment on this safety case.

4. The manufacturer publicly addresses these comments.

5. The agency determines that the manufacturer has presented a reasonable safety case.

6. The manufacturer certifies that its product adheres to its safety case.

7. The manufacturer sells that product.

This process draws on several existing models, including the type approval (or homologation) typical in the European Union and the self-certification prescribed by US law. It could accommodate the kind of process standards used in ISO 26262, the kind of alternatives discussion characteristic of environmental impact statements, and the kind of public dialogue foundational to notice-and-comment rulemaking.

By encouraging companies to disclose information necessary to their safety case, such an approach could help educate regulators and the broader public about the capabilities and limitations of these emerging technologies. Although disclosure could justifiably concern some developers, this process would not require the disclosure of all information, only that which is necessary to demonstrate a reasonable safety case. What is reasonable will likely evolve, and this approach could afford companies greater flexibility to make nontraditional arguments for the safety of their systems and regulators greater flexibility to adapt to changing capabilities.

Because flexibility can also mean uncertainty, early collaboration between regulators and developers may be necessary to avoid all-or-nothing approval decisions at the end of product development. Regardless, uncertainty is not a new concern: Whatever clarity that the current 
federal regime offers through self-certification to specific standards is diminished by the recalls and lawsuits that can arise years or even decades after a vehicle has been sold.

Indeed, unlike current federal motor vehicle safety standards, a safety case could contemplate the entire product lifecycle. A developer might describe not only the steps it had taken to ensure reasonable safety at the time of sale but also the steps it would continue to take as it learned more about performance in the field.

\subsection{Simplify the Problem}

\subsubsection{Limit the Duration of Risk}

The potential longevity of any motor vehicle - the "average" age of cars in the United States is more than eleven years [15] - can create uncertainty for its manufacturers [21] and safety concerns for the public [26]. In 2013, Chrysler reluctantly recalled some Jeeps that were twenty years old [9], [13]. More generally, newer vehicles tend to be safer than older vehicles; "improvements made after the model year 2000 fleet prevented the crashes of 700,000 vehicles; prevented or mitigated the injuries of 1 million occupants; and saved 2,000 lives in the 2008 calendar year alone" [8].

This uncertainty may be particularly great in the case of automated vehicles [21]. Even extensive testing may not capture the full range of scenarios that these vehicles could face. Manufacturers may have difficulty predicting "the eventual response of judges, juries, regulators, consumers, and the public at large to incidents that will inevitably occur" [28]. Regulators may be "concerned that, first, isolated incidents involving these products will create feelings of helplessness and panic that unjustifiably stymie their wider adoption and that, second, these early products will still be around years later when they are much less safe than whatever has become state of the art" [26].

A promising response to these challenges is a lifecycle approach to vehicle design that seeks to limit the duration of risk. For the private sector, this could entail over-the-air updates, end-user license agreements, leasing arrangements, and a variety of other technical and legal tools to enable manufacturers to update or even forcibly retire systems in which they no longer have confidence [21]. For the public sector, this could mean requiring companies to document a strategy and a capacity for monitoring the long-term safety of their systems. Such documentation could be a key part of the safety case introduced above.

\subsubsection{Exclude the Extreme}

The aphorism that "the perfect is the enemy of the good" [33] is instructive for vehicle automation. Demanding perfection may impede the development or deployment of systems that, while not perfect, nonetheless represent a significant improvement over conventional vehicles. Excessive design demands, for example, might preclude an automated vehicle 
that could avoid many of the common errors of human drivers but that could not avoid catastrophic multicar freeway pileups to the extent physically possible. In other words, it may be prudent to accept some failures in order to expedite larger successes.

Moreover, attempting to design an automated vehicle to handle every conceivable driving scenario may introduce complexity that is poorly understood, unmanageable, and ultimately detrimental to safety. Again, for example, designing an automated vehicle to rapidly accelerate through a pileup-in-progress might lead to programming oversights that could cause that same vehicle to errantly speed up after entering a closed construction zone. Here it may be prudent to accept some failures in order to prevent even more catastrophic failures.

For both of these reasons, early generations of automated vehicles may necessarily limit the technical challenges that they attempt to solve. These vehicles might be deployed into simplified environments at lower speeds [22]. Or they might continue to rely in part on human drivers [29], particularly if those humans are professionals who can be carefully trained, closely monitored, and sufficiently incentivized.

Sound engineering may demand additional limitations. For example, it may be prudent to program an automated vehicle to never speed, to always slow to a stop in the event of a detected failure, or to always permit human override within a set number of seconds. These stylized examples might mean that, in occasional cases, an automated vehicle will crash because it has failed to accelerate or because it has stopped or because its human driver has made poor decisions while panicking.

Although these should be primarily technical determinations, law may be able to play a supporting role. In some jurisdictions, for example, the plaintiff in a product liability case must demonstrate that an alternative product design was available and superior to the one alleged to have contributed to her injury. In such a case, it may be appropriate to give more weight to counterarguments about the complexity, uncertainty, and delay inherent in such designs.

There are, however, two important cautions. First, for those injuries that do occur, this strategy merely shifts more of the risk to those people who have been injured. This consequence highlights the need for a sufficient social safety net, whether provided through public insurance, private insurance, or another means. Second, codifying a ceiling on the performance required could mean calcifying the level of reasonable design for technologies that may quickly be capable of much more.

\subsection{Raise the Playing Field}

\subsubsection{Reject the Status Quo}

The reality that human drivers often violate rules of the road prompts speculation that programming automated vehicles to comply with these rules would reduce their appeal. Suggestions for addressing this perceived disadvantage have included expressly permitting 
automated vehicles to travel at or above the prevailing traffic speed and delegating decisions about speed or aggression to the human users of these vehicles.

Drivers, however, currently behave in ways that are neither lawful nor reasonable [20]. They drive too fast for conditions, they follow other vehicles too closely, and they fail to yield the right of way to pedestrians. They drive while intoxicated or distracted. They fail to properly maintain their vehicles' tires, brakes, and lights. These largely unlawful behaviors occasionally result in crashes, and those crashes occasionally result in serious injury. This tragic status quo suggests that the current approach to traffic enforcement should be reformed rather than transferred to automated vehicles.

At this early stage in automation, transportation authorities would do better to optimize and then enforce rules of the road for all motor vehicles. Increasing the expectations placed on human drivers - by cracking down on speeding, texting, drunk driving, and other dangerous activities - could increase the appeal of automated vehicles at least as much as allowing those automated vehicles to speed.

Automated enforcement could be a key tool for increasing compliance. Such enforcement currently relies both on roadway devices (including speed and red light cameras) and on in-vehicle devices (including alcohol locks, speed regulators, and proprietary data recorders). Private entities such as fleet managers and insurance companies already provide some of this enforcement indirectly through private incentives. The potential proliferation of outward-facing cameras on vehicles and drones in the air might also facilitate increased public and private enforcement of rules of the road.

Increased enforcement could, on one hand, address equity concerns of discretionary enforcement and, on the other hand, raise privacy and liberty concerns. While these are important questions, a status quo in which laws are openly flouted even by the officers enforcing them is one that begs for reform.

Indeed, more consistent and comprehensive enforcement could create pressure for a careful evaluation of existing law. Better access to and analysis of location-specific information about the driving environment (including roadway geometry, pavement, traffic, and weather) could enable the precise calibration of dynamic speed limits. These dynamic limits might then be communicated to drivers through variable message signs and, in the future, vehicle-to-infrastructure communication.

Because reasonable speed also depends on the driver and her vehicle, posted limits might nonetheless have only limited utility. Pursuant to the basic speed law [20], a human driver should account for each of these variables implicitly and adjust her speed accordingly. Automated vehicles, however, may account for more of these variables explicitly - and reasonably.

Consider, for example, the common requirement that the "driver of a vehicle shall yield the right-of-way to a pedestrian crossing the roadway within any marked crosswalk or ... unmarked crosswalk at an intersection, except as otherwise provided" [6]. Although pedestrians may not create an "immediate hazard" by "suddenly" leaving the curb [6], the statutory obligation to yield does suggest one possible bound on vehicle speed. 
Figure 27.2 Illustration of Vehicle Stopping

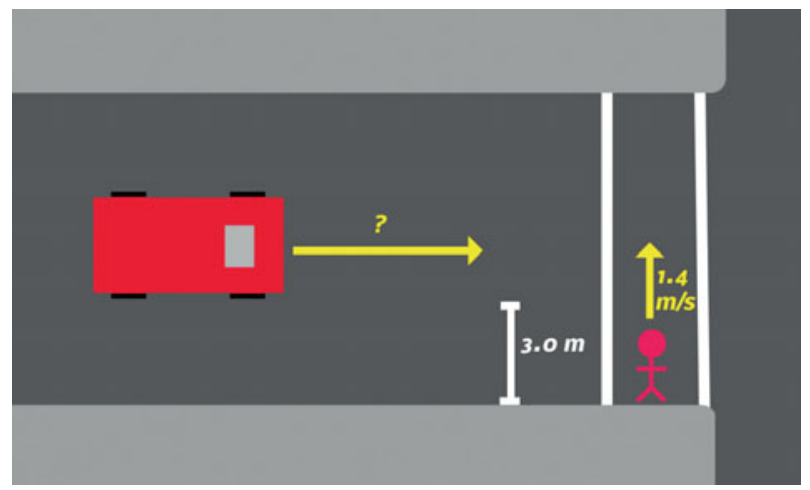

Imagine a driver traveling down a typical neighborhood street with a parking lane that provides $3 \mathrm{~m}$ between her car and the curb, as shown in Figure 27.2. Assuming that her view of the pedestrian is not blocked, what maximum speed will enable this driver to stop for any pedestrian who, at a walking speed of $1.4 \mathrm{~m} / \mathrm{s}$, steps from the curb into the street?

Although stopping sight distance depends on several vehicle, environment, and driver variables [1], this illustration simplifies these to consider only the driver's reaction time and the friction between the tires and the road surface. An average driver with good tires on a flat dry street might achieve a reaction time of $1 \mathrm{~s}$ and a subsequent deceleration rate of $5 \mathrm{~m} / \mathrm{s}^{2}$, which implies a maximum speed of $20 \mathrm{~km} / \mathrm{h}(13 \mathrm{mph}){ }^{4}$ In contrast, a hypothetical automated vehicle reacting twice as fast and braking at $7 \mathrm{~m} / \mathrm{s}^{2}$ could reach a maximum speed of about $40 \mathrm{~km} / \mathrm{h}(25 \mathrm{mph}),{ }^{5}$ which is a typical residential speed limit today. In other words, if automated vehicles are traveling slowly on a road, perhaps conventional vehicles should be traveling even more slowly.

Reasonable speed is also an answer to some, though not all, of the ethical dilemmas popularly raised in the context of automated driving [10], [32]. Positing a choice between killing one group of pedestrians and another, for example, fails to account for the possibility of negating the dilemma simply by driving more slowly. Slower speeds can increase controllability as well as reduce the magnitude of harm.

Speed is not the only relevant driver action. Tire condition, for example, is an important consideration in stopping distance, is at least nominally regulated [2], and yet varies widely within the current vehicle fleet. If the hardware on automated vehicles is expected to be regularly inspected, so too should the hardware on conventional vehicles. Moreover,

4 initial speed $=$ rate of deceleration $*(($ pedestrian speed $/$ orthogonal distance from curb to car $)$ - reaction time $)=\left(0.5 * 9.8 \mathrm{~m} / \mathrm{s}^{2}\right) *(((1.4 \mathrm{~m} / \mathrm{s}) / 3 \mathrm{~m})-1 \mathrm{~s})=6 \mathrm{~m} / \mathrm{s}=20 \mathrm{~km} / \mathrm{h}=13 \mathrm{mph}$.

5 initial speed $=$ rate of deceleration $*(($ pedestrian speed $/$ orthogonal distance from curb to car $)$ - reaction time $)=\left(0.7 * 9.8 \mathrm{~m} / \mathrm{s}^{2}\right) *(((1.4 \mathrm{~m} / \mathrm{s}) / 3 \mathrm{~m})-0.5 \mathrm{~s})=11 \mathrm{~m} / \mathrm{s}=41 \mathrm{~km} / \mathrm{h}=25 \mathrm{mph}$. 
driving imposes environmental costs that are not internalized by vehicle owners and operators [18]. If automated driving proves to be more fuel efficient than human driving, a higher fuel tax would also incentivize automation.

In short, reform should seek to more closely align what is lawful with what is reasonable and to more closely align actual driver behavior with both [20]. The expectation that both automated vehicles and human drivers should behave reasonably is itself reasonable and ultimately advantageous to automated driving.

\subsubsection{Embrace Enterprise Liability}

Although vehicle automation will change the way some cases are litigated and resolved, manufacturers are likely to continue to successfully manage their product liability [28]. Uncertainty about liability is probably more of an impediment to product deployment than actual exposure to liability - and there are strategies that companies can take to manage that uncertainty [21].

This confidence, however, is not universal [11]. A more skeptical view even has precedent: The National Childhood Vaccine Injury Act of 1986 was passed in response to similar concerns that traditional product liability had rendered some vaccines uneconomic for their would-be producers. The regime it created "combines procedural and substantive limitations on conventional tort remedies with an alternative compensation scheme for probable victims of covered vaccines" [21].

If product liability exposure does impede the deployment of automated vehicles, a similar regime might be an effective response. However, that is by no means the only conceivable alternative.

Rather than limiting liability for the manufacturers of automated systems, courts or legislatures could expand liability for everyone else. This is counterintuitive and, as a legislative proposal, unlikely to go anywhere. Nonetheless, consider the consequences of introducing a system of enterprise liability in which manufacturers are liable for all harm associated with their products. In other words, what would be different if automakers could be successfully sued for every crash involving their product rather than just the small fraction in which a vehicle defect contributed to the injury?

Some effects would be undesirable. Automakers might outright refuse to sell their vehicles in any jurisdiction with enterprise liability. Others would demand higher prices to cover their increased costs. This could in turn mean less access for consumers, particularly those with limited resources.

Other effects, however, might arguably be more desirable. No longer would dealers simply hand over car keys to new buyers. Instead, manufacturers might require these buyers to complete more thorough driver training customized for the particular vehicle. Technologies like alcohol-sensing ignition locks and speed regulators might become standard. Older vehicles might be promptly removed from roads as safer systems are introduced. A notable result could be safer roads. 
Another result could be greater automation: Given the choice between paying for the mistakes of their own technologies and paying for the mistakes of their disparate customers, many companies would likely opt for their technology. Automation would become a solution to rather than merely a source of litigation.

Even if pure enterprise liability remains a thought experiment, its principles are evident in other areas relevant to automation. Fleet operators are an attractive market for automated vehicles in part because they are already liable for injuries caused by the negligence of their drivers. Automation may also offer near-term financial or market advantages to insurers, which similarly pay for injuries caused by their insured.

More broadly, as manufacturers gain and assert more control over the products they have sold through technology and contract, they may also incur greater legal obligations in tort [21]. These obligations, which might approach enterprise liability without actually reaching it, could have a similar effect on design decisions. Eventually, selling a vehicle that lacks safety-critical automation features might itself be unreasonable.

\subsection{Conclusion}

This chapter began with two fundamental questions: How should risk be allocated in the face of significant uncertainty - and who should decide? Its focus on public actors reflects the significant role that legislatures, administrative agencies, and courts will play in answering these questions, whether through rules, investigations, verdicts, or other forms of public regulation.

The eight strategies discussed above would in effect regulate that regulation. They seek to ensure that those who are injured can be compensated, that any prospective rules develop in tandem with the technologies to which they would apply, that reasonable design choices receive sufficient legal support, and that conventional driving is subject to as much scrutiny as automated driving. Table 27.2 (below) summarizes.

Table 27.2 Potential Regulatory Strategies

\section{Ensure sufficient compensation for those who are injured}

\begin{tabular}{l|l} 
Expand public insurance & Facilitate private insurance
\end{tabular}

Force information-sharing by the private sector to enhance regulation

Privilege the concrete Delegate the safety case

Simplify both the technical and the regulatory challenges in coordination

\begin{tabular}{l|l} 
Limit the duration of risk & Exclude the extreme
\end{tabular}

Raise the playing field for conventional actors along with automated systems

Reject the status quo Embrace enterprise liability 
This focus on public actors does not diminish the important roles that private actors play in innovation and in regulation. Indeed, several of the strategies discussed above expressly embrace these roles. In this spirit, a challenge for - and to - developers of automated systems is to contribute fully and publicly to the broader discussions for which these strategies are intended.

\section{References}

1. AASHTO, A Policy on Geometric Design of Highways and Streets (Green Book), 6th Edition (2011)

2. Blythe, William and Seguin, Debra E., Commentary: Legal Minimum Tread Depth for Passenger Car Tires in the U.S.A. - A Survey, Traffic Injury Prevention, vol. 7, issue 2 (2006)

3. California DMV Regulations, Title 13, § 227

4. California Insurance Code $\S 11580.1 \mathrm{~b}$

5. California Proposition 103 (1988)

6. California Vehicle Code $\S 21950$

7. Chrysler Corp. v. Dept. of Transp., 472 F2.d 659, 676 (6th Cir. 1972)

8. Glassbrenner, Donna, An Analysis of Recent Improvements to Vehicle Safety, http://www-nrd. nhtsa.dot.gov/Pubs/811572.pdf

9. Keane, Angela Greiling, Chrysler Refusal on Jeeps Sets Challenge to Recall Power, June 7, 2013, http://www.bloomberg.com/news/2013-06-07/chrysler-refusal-on-jeeps-sets-challenge-torecall-power.html

10. Lin, Patrick, Why Ethics Matters for Autonomous Cars, in this book

11. Marchant, Gary E. and Lindor, Rachel A., The Coming Collision Between Autonomous Vehicles and the Liability System, Santa Clara Law Review (2012)

12. Michigan Compiled Laws Sec. 22949b

13. NHTSA Letter from Jennifer Timian, NHTSA, to Matthew Liddane, Chrysler Group LLC, June 21, 2013, http://www-odi.nhtsa.dot.gov/acms/cs/jaxrs/download/doc/UCM440558/RCAK13V252-1688.PDF

14. N.Y. VEH. \& TRAF. LAW § 400 (McKinney 2013)

15. Press Release, Polk, Polk Finds Average Age of Light Vehicle Continues to Rise (Aug. 6, 2013), https://www.polk.com/company/news/polk_finds_average_age_of_light_vehicles_continues_ to_rise

16. Pritchard, Justin, How Google Got States to Legalize Driverless Cars, http://bigstory.ap.org/article/how-google-got-states-legalize-driverless-cars (2014)

17. Roberts, Stephen N., Hightower, Alison S., Thornton, Michael G., Cunningham, Linda N., and Terry, Richard G., Advanced Vehicle Control Systems: Potential Tort Liability for Developers, FHWA Contract DTFH61-93-C-00087 (Dec. 1, 1993)

18. Small, Kenneth A. and Kazimi, Camilla, On the Costs of Air Pollution from Motor Vehicles, Journal of Transport Economics and Policy (1995)

19. Smith, Bryant Walker (2014a), Automated Vehicles Are Probably Legal in the United States, 1 Texas A\&M Law Review 411 (2014), http://newlypossible.org

20. Smith, Bryant Walker (2014b), Lawyers and Engineers Should Speak the Same Robotic Language, forthcoming in Robot Law (2014), http://newlypossible.org

21. Smith, Bryant Walker (2014c), Proximity-Driven Liability, 102 Georgetown Law Journal 1777 (2014), http://newlypossible.org 
22. Smith, Bryant Walker (2014d), A Legal Perspective on Three Misconceptions in Vehicle Automation, in Sven Beiker and Gereon Meyer, Vehicle Automation, Springer Lecture Notes in Mobility (2014), http://newlypossible.org

23. Smith, Bryant Walker (2014e), Something Interest in California's New Automated Vehicle Testing Rule, http://cyberlaw.stanford.edu/blog/2014/05/something-interesting-californiasnew-automated-vehicle-testing-rule

24. Smith, Bryant Walker (2013a), Taxonomy of Regulation (TRB), reprinted in Handbuch Fahrassistenzsysteme (2014)

25. Smith, Bryant Walker (2013b), The Reasonable Self-Driving Car, http://www.volokh. com/2013/10/03/reasonable-self-driving-car

26. Smith, Bryant Walker (2013c), Automated Vehicles Are Probably Legal in the United States, http://cyberlaw.stanford.edu/blog/2013/04/automated-vehicles-are-probably-legal-united-states

27. Smith, Bryant Walker (2013d), Planning for the Obsolescence of Technologies Not Yet Invented, http://cyberlaw.stanford.edu/blog/2013/10/planning-obsolescence-technologies-not-yet-invented

28. Smith, Bryant Walker (2013e), Uncertain Liability, http://cyberlaw.stanford.edu/blog/2013/05/ uncertain-liability

29. Smith, Bryant Walker (2013f), SAE's Levels of Driving Automation, http://cyberlaw.stanford. edu/loda

30. Smith, Bryant Walker (2012a), Autolaw 3.0, TRB Workshop on Road Vehicle Automation (2012)

31. Smith, Bryant Walker (2012b), How an (Autonomous Driving) Bill Becomes Law, http:// cyberlaw.stanford.edu/events/how-autonomous-driving-bill-becomes-law

32. Smith, Bryant Walker (2012c), Driving at Perfection, http://cyberlaw.stanford.edu/blog/2012/03/ driving-perfection

33. Voltaire, La Bégueule

34. Weiner, Gabriel and Smith, Bryant Walker, Automated Driving: Legislative and Regulatory Action, http://cyberlaw.stanford.edu/wiki/index.php/Automated_Driving:_Legislative_and_ Regulatory_Action

35. Wood, Stephen P., Chang, Jesse, Healy, Thomas, and Wood, John, The Potential Regulatory Challenges of Increasingly Autonomous Motor Vehicles, 52 Santa Clara Law Review 1423 (2012) 